\title{
Modeling Study of Rotational Relaxation and Absorption
}

Prepared by W. C. HWANG and R. F. KAMADA

Chemistry and Physics Laboratory

20 January 1977

Prepared for

VICE PRESIDENT AND GENERAL MANAGER

THE IVAN A. GETTING LABORATORIES

The Ivan A. Getting Laboratories

THE AEROSPACE CORPORATION 


\section{DISCLAIMER}

This report was prepared as an account of work sponsored by an agency of the United States Government. Neither the United States Government nor any agency Thereof, nor any of their employees, makes any warranty, express or implied, or assumes any legal liability or responsibility for the accuracy, completeness, or usefulness of any information, apparatus, product, or process disclosed, or represents that its use would not infringe privately owned rights. Reference herein to any specific commercial product, process, or service by trade name, trademark, manufacturer, or otherwise does not necessarily constitute or imply its endorsement, recommendation, or favoring by the United States Government or any agency thereof. The views and opinions of authors expressed herein do not necessarily state or reflect those of the United States Government or any agency thereof. 


\section{DISCLAIMER}

Portions of this document may be illegible in electronic image products. Images are produced from the best available original document. 


\section{THE IVAN A. GETTING LABORATORIES}

The Laboratory Operations of The Aerospace Corporation is conducting experimental and theoretical investigations necessary for the evaluation and application of scientific advances to new military concepts and systems. Versatility and flexibility have been developed to a high degree by the laboratory personnel in dealing with the many problems encountered in the nation's rapidly developing space and missile systems. Expertise in the latest scientific developments is vital to the accomplishment of tasks related to these problems. The laboratories that contribute to this research are:

Aerophysics Laboratory: Launch and reentry aerodynamics, heat transfer, reentry physics, chemical kinetics, structural mechanics, flight dynamics, atmospheric pollution, and high-power gas lasers.

Chemistry and Physics Laboratory: Atmospheric reactions and atmospheric optics, chemical reactions in polluted atmospheres, chemical reactions of excited species in rocket plumes, chemical thermodynamics, plasma and laser-induced reactions, laser chemistry, propulsion chemistry, space vacuum and radiation effects on materials, lubrication and surface phenomena, photosensitive materials and sensors, high precision laser ranging, and the application of physics and chemistry to problems of law enforcement and biomedicine.

Electronics Research Laboratory: Electromagnetic theory, devices, and propagation phenomena, including plasma electromagnetics; quantum electronics, lasers, and electro-optics; communication sciences, applied electronics, semiconducting, superconducting, and crystal device physics, optical and acoustical imaging; atmospheric pollution; millimeter wave and far-infrared technology.

Materials Sciences Iahnratory: Development of new materials; metal matrix composites and new forms of carbon; test and evaluation of graphite and ceramics in reentry; spacecraft materials and electronic components in nuclear weapons environment; application of fracture mechanics to stress corrosion and fatigue-induced fractures in structural metals.

Space Sciences Laboratory: Atmospheric and ionospheric physics, radiation from the atmosphere, density and composition of the atmosphere, aurorae and airglow; magnetospheric physics, cosmic rays, generation and propagation of plasma waves in the magnetosphere; solar physics, studies of solar magnetic fields; space astronomy, x-ray astronomy; the effects of nuclear explosions, magnetic storms, and solar activity on the earth's atmosphere, ionospherc, and magnetosphere; the effects of optical, electromagnetic, and particulate radiations in space on space systems.

THE AEROSPACE CORPORATION 
Aerospace Report No. ATR $-77(8127)-3$

MODELING STUDY OF ROTATIONAL RELAXATION AND ABSORPTION

$$
\text { Prepared by }
$$

W. C. Hwang and R. F. Kamada $q 50$

Chemistry and Physics Laboratory

The Aerospace Corporation

$$
20 \text { January } 1977
$$

The Ivan A. Getting Laboratories THE AEROSPACE CORPORATION

El Segundo, Calif. 90245

$$
\text { Prepared for }
$$

\section{VICE PRESIDENT AND GENERAL MANAGER}

THE IVAN A. GETTING LABORATORIES

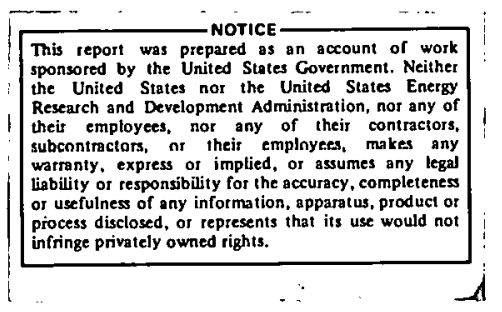


THIS PAGE

\section{WAS INTENTIONALLY LEFT BLANK}


Report No.

AIR $-77(8127)-3$

MODELING STUDY OF ROTATIONAL

RELAXATION AND ABSORPTION

Prepared
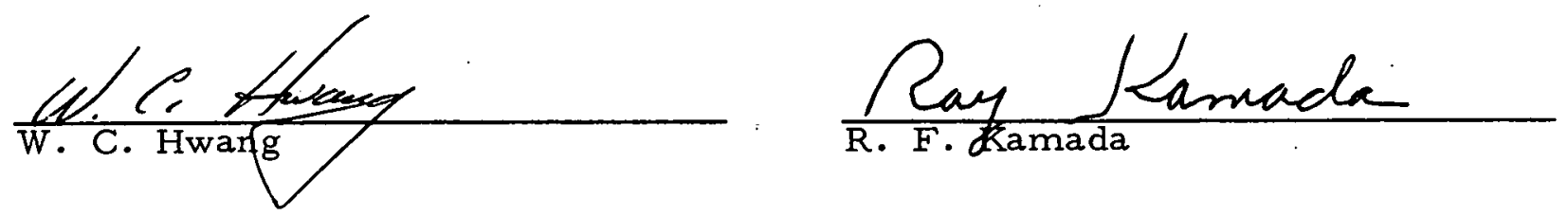

Approved

Rid. moral

R. J. AnNeal, Head

Chemical Physics Department

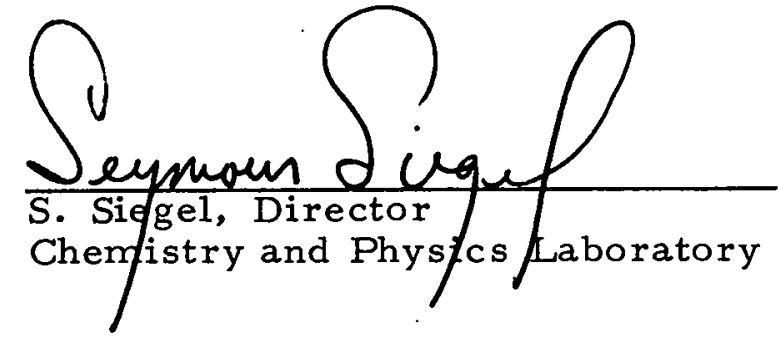

Chemistry and Physios Laboratory

-iii -: 


\section{ACKNOW LEDGMENT}

The assistance of Cyrus Kamada in evaluation of solutions to differential equations is gratefully acknowledged. This work was supported by The Aerospace Corporation on Company funds and by the Energy Research and Development Administration under Contract No. E(04-3)-1017. 


\begin{abstract}
The rate of rotational relaxation can influence the amount of single-line absorption for a transition that involves discrete rotational states. The extent of selected-state laser chemistry can thus be affected by the rotational bottleneck effect. Models of rotational relaxation and pulsed single-line absorption have been constructed to determine the main factors governing the bottleneck effect, to determine the relaxation rate constants necessary to maintain equilibrium for a wide range of conditions, and to investigate the effects of rotational relaxation in a two-step photodissociative isotope en richment scheme. Coupling the models with laboratory experiments could also yield a new method for determining rotational relaxation rates.
\end{abstract}




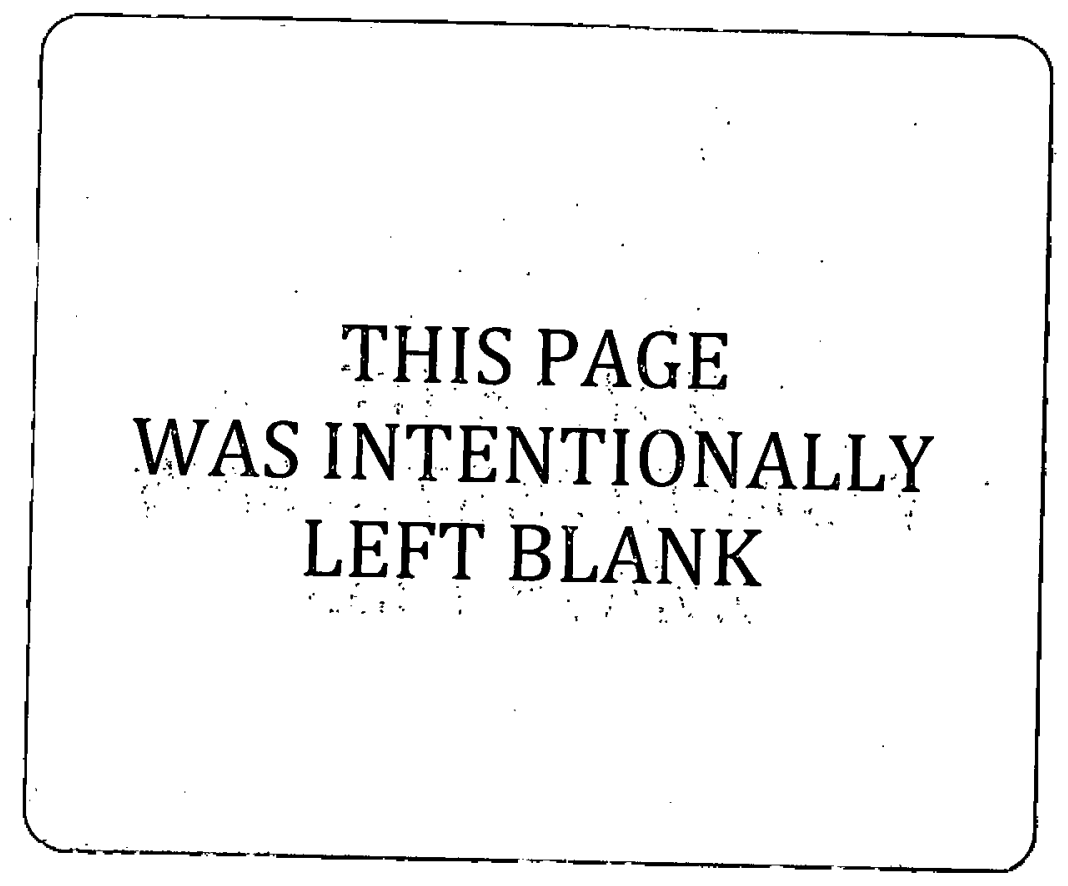


CONTENTS

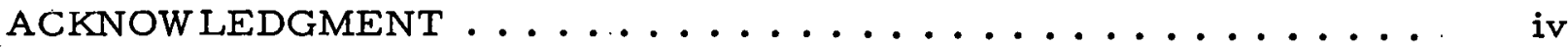

ABSTRACT $\ldots \ldots \ldots \ldots \ldots \ldots \ldots \ldots$

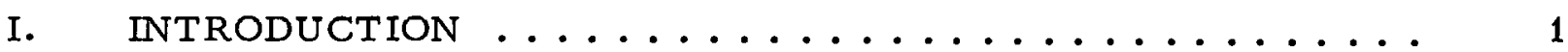

II. CONSTRUGTION OF MODELS .................. 3

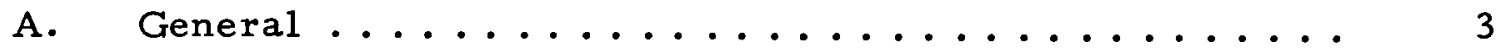

B. Rotational-Translational States and Interconnecting Processes ............... 3

C. Analytical Models ..................... 7

D. Numerical Models .................... 10

E. Enrichment Models ................... 10

III. $\operatorname{RESULTS\ldots \ldots \ldots \ldots \ldots \ldots \ldots \ldots } 13$

A. Analytical Models ..................... 13

B. Numerical Models .................... 20

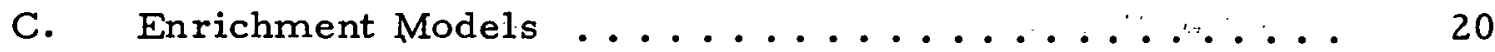

D. Coupling of Models and Experiments ........... 23

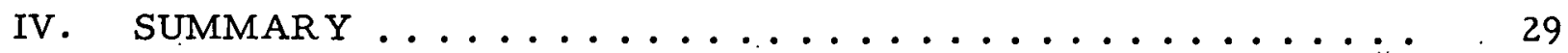
APPENDIXES

A. CALCULATION OF ALPHA AND GAMMA .......... 31

B. COUPLING OF TRANSLATIONAL AND ROTATIONAL RELAXATION .............. 33

C. CALCULATION OF ART, ROTATIONALTRANSLATIONAL RELAXATION CASE $\ldots \ldots \ldots$

D. CALCULATION OF $A_{R}$ AND $A_{E} \ldots \ldots . \ldots . \ldots . \ldots$

E. INPUTS FOR BASE CONDITIONS OF ENRICHMENT MODELS ................. 39

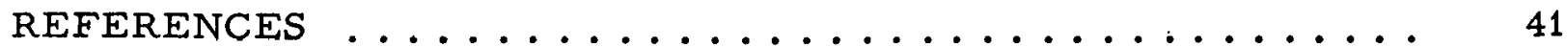




\section{TABLES}

1. Variation of Degeneracy Ratio and Delta ........... 22

2. Results of Enrichment Models .................. 24

3. $\mathrm{HBr}$ Absorption for Mixtures of $\mathrm{HBr}$ and $\mathrm{NO} \ldots \ldots . \ldots 25$

4. $\mathrm{HBr}$ Absorption for Mixtures of $\mathrm{HBr}, \mathrm{I}_{2}$, and $\mathrm{Ar} \ldots \ldots$

5. Sensitivity of Absorption to Rotational Relaxation Rate . . . . . 28

\section{FIGURES}

1. Rotational-Translational Model ................. 5

2. Variation of Rotational Relaxation Rate ............... 14

3. Variation of Laser Puls ewidth ................ 15

4. Variation of Rotational Partition Coefficients .......... 17

5. Variation of Translational Relaxation Rate ........... 18

6. Rotational Model and Translational Model ............ 19

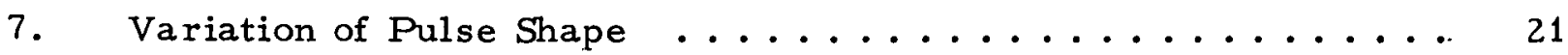




\section{INTRODUCTION}

The extent of state-selected laser chemistry depends on the number of selectively excited species produced by laser absorption. For absorption of intense laser radiation involving discrete rotational states (without nonlinear effects), the amount of absorption is governed by the rate and duration of the absorption procoos and the rotatiunal relaxation rate. When rotational relaxation rates are very fast compared with absorption rates, and equilibrium is maintained, the population of the whole rotational manifold is accessible to the absorption process. At the other extreme, when no relaxation occurs, only the populations of the individual rotational states that interact directly with the radiation are accessible. For conditions between these extremes, finite rotational relaxation rates can determine the amount of absorption.

The importance of rotational relaxation to selected-state chemistry was discussed by Letokhov ${ }^{1}$ and demonstrated in the isotope separation studies of Ambartzumian and co-workers ${ }^{2}$ and Lyman and Rockwood, 3,4 in which evidence is given for limitation of excitation by the rotational bottleneck effect. Previous models of selected-state chemistry, however, assumed rotational equilibrium during absorption. ${ }^{5,6}$ Thus, a model that includes the effects of rotational relaxation on absorption is needed.

In this study, models of single-line absorption and rotational relaxation were constructed to: (1) determine the amount of absorption for various relaxation conditions; (2) determine the rotational relaxation rate constants necessary to maintain equilibrium for a wide range of experimental conditions; and (3) investigate the effects of rotational relaxation in a two-step is otope enrichment scheme. A simple model for translational or velocity relaxation is used to determine the conditions under which translational relaxation must be considered as well. 


\section{$\because 3 \%$ क}

THISPAGE WAS INTENTIONALLY LEFT BLANK 


\section{CONSTRUCTION OF MODELS}

\section{A. GENERAL}

The significance of rotational and velocity relaxation under any conditions is determined by comparing the total absorption in a model with finite relaxation rates to that of an equilibrium model (with infinite rates). Three sets of models are usèd; each set contains an equilibrium model and at least one finite relaxation model. The analytical models are used to determine the amount of absorption under finite relaxation conditions and the relaxation rate needed to approximate equilibrium. The numerical models are used to investigate limits of the analytical models. The enrichment models show the effect of rotational relaxation when the models are applied to a particular laser isotope enrichment experiment.

In all cases, pulsed, single-line laser absorption is modeled. The rate of net absorption $\mathrm{dA} / \mathrm{dt}$ is given by.

$$
\mathrm{dA} / \mathrm{dt}=\mathrm{kI}\left(\mathrm{C}_{1}-\mathrm{gC}_{\mathrm{u}}\right)
$$

where $I$ is the laser intensity in photons $/ \mathrm{cm}^{3}, C_{1}$ and $C_{u}$ are the concentrations in molecules $/ \mathrm{cm}^{3}$ of the lower and upper stages of the transition, respectively, $k$ is the absorption rate constant in $\mathrm{cm}^{3} /$ molecules $-\mathrm{sec}$, and $\mathrm{g}$ is the degeneracy ratio of the lower to upperstates. The usually small effects of spontaneous emission are ignored.

Cell dimensions in the model are sufficiently small that the laser intensity is not significantly perturbed by absorption; thus; the systems have spatial uniformity. This assumption should not be very limiting because most laser sources have great spectral brightiness.

\section{B. ROTATIONAL-TRANSLATIONAL STATES AND}

\section{INTERCONNECTING PROCESSES}

The absorption of single-line radiation connecting discrete rotational states results in nonequilibrium rotational distributions in both the upper 
and lower manifolds of the transition. A strong perturbation of the upper manifold caused by absorption coupled with saturation effects (when net absorption is reduced significantly by stimulated emission) can reduce the amount of absorption relative to the equilibrium case. In all finite rotational relaxation models, both the upper and lower manifolds are divided into two states, $R_{i}$ and $R_{j}$. The rotational state that can directly interact with laser radiation is $r_{i}$; all other states are lumped into $R_{j}$.

A second relaxation process that can influence absorption is translational or velocity relaxation, particularly for the narrow laser linewidth and low pressure conditions found in many laser state-selected studies. For inhomogeneous broadening conditions (low pressures) and a laser line that is narrower than the Doppler absorption line, radiation can interact only with molecules that have proper velocity components. Whenever the absorption rate is too fast for translational or velocity relaxation processes to maintain an equilibrium velocity distribution, hole burning of the absorption line occurs, and the amount of absorption is reduced relative to the homogeneous case.

In the rotational-translational model, each $R_{i}$ state (or level) is subdivided into two translational states, $R_{i} T_{i}$ and $R_{i} T_{j}$, as shown in Fig. 1 , where superscript $u$ denotes the upper level of the transiliun and 1 the lower level. The molecules in the $R_{i} T_{i}$ state are the only ones that can interact with the radiation in the low-pressure or inhomogeneous Doppler-shaped limit. As pressure increases, line broadening from collisions becomes more prominent, and the absorption line takes on more homogeneous char acter. Molecules in the $R_{i} T_{j}$ state can then interact with the radiation but with a lower rate constant. The absorption (processes 1 and 2) can be a vibrational-rotational transition involving one electronic level or a vibrorotonic transition involving two electronic levels. For process 1, the forward rate constant $K_{1 F}$ equals $k I$, whereas $K_{1 B}=$ gkI for the backward process. The rate constant for absorption $\mathrm{K}_{\mathrm{L}}$ used in the calculations is considered to be equal to $K_{1 F}+K_{1 B}$. Similarly, $K_{2 F}=a K_{1 F}=\operatorname{akI}$ and $K_{2 B}=$ agkI, where the value of a varies from zero (low-pressure limit, strictly 


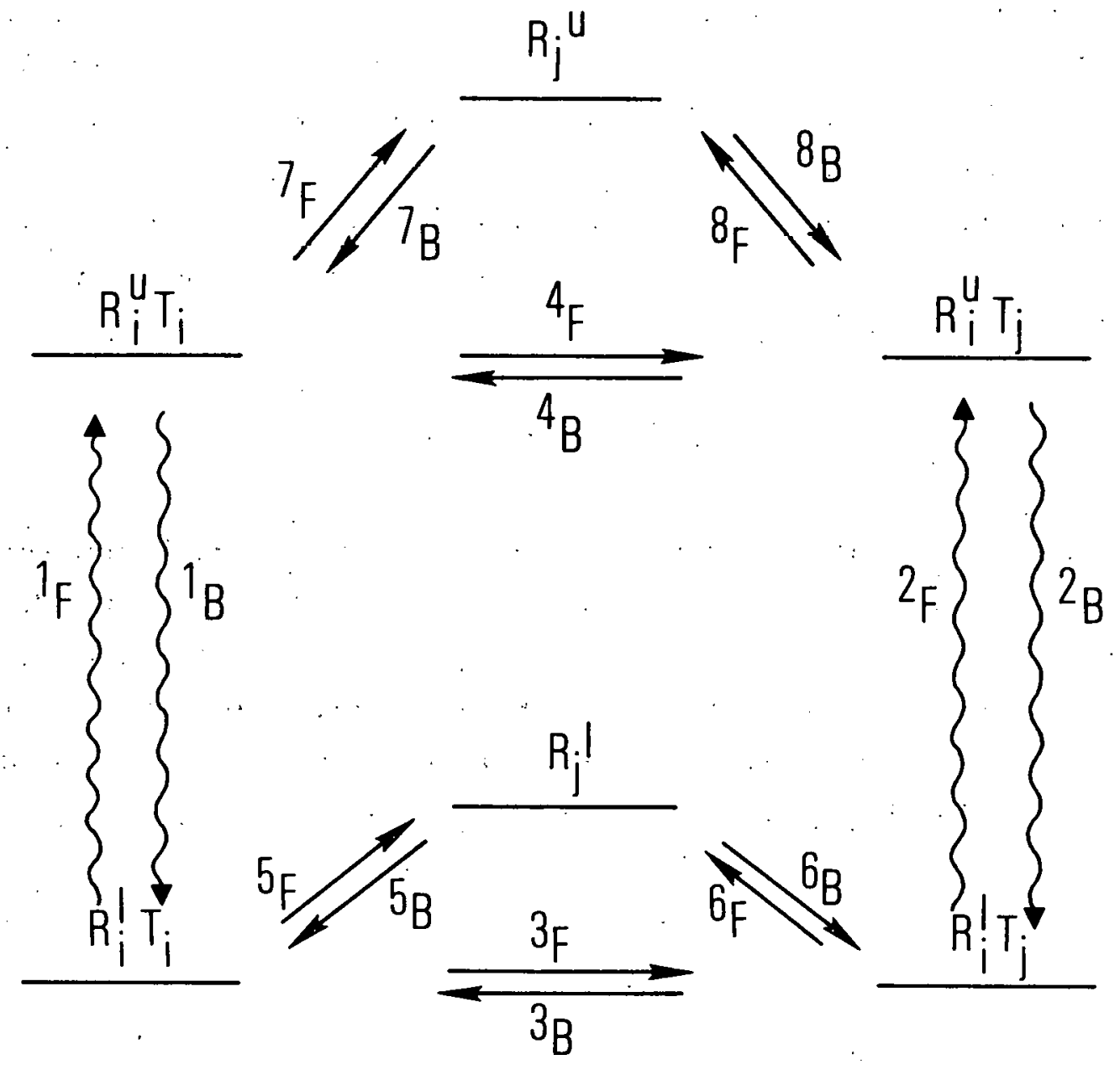

Figure 1. Rotational-Translational Model 
Gaussian inhomogeneously broadened line) to one (high-pressure limit, strictly Lorentzian homogeneously, broadened line). Its value is a function of the Doppler width (HWHM) of the absorption line $\Delta \gamma_{D^{\prime}}$, the laser linewidth (HWHM) $\Delta v_{L}$, and the rate of line broadening collisions. The method of calculating $a$ is given in Appendix I. The translational relaxation rate contatnt $K_{T}$ is defined to be equal to $K_{i F}+K_{i B}$ for $i=3,4$.

Translational relaxation and rotational relaxation are represented by processes 3 through 4 and 5 through 8 , respectively. The net rate of relaxation for the $i^{\text {th }}$ relaxation processes is

$$
K_{i F} C_{i F}-K_{i B} C_{i B}
$$

where $C$ is the reactant concentration, and subscripts $F$ and $B$ represent the forward and backward processes, respectively. In all model runs, the K's are assumed to be constant with respect to reactant concentration. This pseudo first-order assumption is valid except for conditions where selfrelaxation is dominant. The dependence on concentration can be included in the numerical and enrichment models. $\mathrm{K}_{\mathrm{iF}}$ and $\mathrm{K}_{\mathrm{iB}}$ are given by

$$
\begin{array}{ll}
\mathrm{K}_{\mathrm{iF}}=(1-\alpha) \sum_{\mathrm{k}} \mathrm{K}_{\mathrm{k}}^{\mathrm{i}} \mathrm{C}_{\mathrm{k}} & \mathrm{i}=3,4 \\
\mathrm{~K}_{\mathrm{iB}}=(\alpha) \sum_{\mathrm{k}} \mathrm{K}_{\mathrm{k}}^{\mathrm{i}} \mathrm{C}_{\mathrm{k}} & \mathrm{i}=3,4
\end{array}
$$

where $K_{k}^{i}$ is the gas kinetic rate constant for a collision between the reactant of the $i^{\text {th }}$ process and the $k^{\text {th }}$ species in the system, $\alpha$ is the fraction of $R_{i}$ molecules in the $R_{i} T_{i}$ state, and the summation is over all species. The method of calculating the translational fraction $\alpha$ is also given in Appendix A.

Rotational relaxation is assumed to involve translational relaxation as well. This as sumption appears reasonable for narrow laser sources 
since only a relatively small change in velocity is necessary to shift a molecule into or out of the resonance laser linewidth region of the Gaussian (low-pressure limit) absorption curve. An example of the energy changes and frequency shift for $\mathrm{HBr}$ is given in Appendix B. If $3 \%$ of the minimum rotational energy change is transmitted into HBr translation along the direction of light propagation; a shift in frequency equal to the estimated laser linewidth of $3 \mathrm{MGz}$ will result.

The $R_{j}$ states are not divided into translational states because of the assumption of coupling of translational with rotational relaxation. The rate constants for rotational relaxation can then be given by

$$
\begin{aligned}
& \mathrm{K}_{\mathrm{iF}}=\delta_{\mathrm{i} \sum_{\mathrm{k}} \mathrm{K}_{\mathrm{k}}^{\mathrm{i}} \mathrm{C}_{\mathrm{k}}} \mathrm{i}=5-8 \\
& \mathrm{~K}_{\mathrm{iB}}=\left\{\begin{array}{lc}
\left(1-\delta_{\mathrm{i}}\right)(\alpha) \sum_{\mathrm{k}} \mathrm{K}_{\mathrm{k}}^{\mathrm{i}} \mathrm{C}_{\mathrm{k}} & \mathrm{i}=5,7 \\
\left(1-\delta_{\mathrm{i}}\right)(1-\alpha) \sum_{\mathrm{k}} \mathrm{K}_{\mathrm{k}}^{\mathrm{i}} \mathrm{C}_{\mathrm{k}} & \mathrm{i}=6,8
\end{array}\right.
\end{aligned}
$$

where $\delta_{i}$ is the equilibrium fraction of molecules in the rotational manifold associated with the $i^{\text {th }}$ processes that are in the $R_{i}$ level (rotational partition coefficient), and $K_{k}^{i}$ is now the rotational relaxation rate constant. The $K_{k}^{i}$ 's are defined to be independent of $\delta_{i}$. The rotational relaxation rate constant $K_{R}$ is equal to $K_{i F}+K_{i B}+K_{(i+1) B}$ and $K_{i F}=K_{(i+1) F}$ for $i=5,7$.

C. ANALYTICAL MODELS

The analytical models are used to determine the amount of absorption for finite relaxation rates and the conditions under which equilibrium is approached. The two finite relaxation systems modeled are coupled rotational-translational relaxation and rotational relaxation. For simplification, the following three constraints are imposed on the systems:

1. Laser pulse with rectangular temporal profile

2. Equal rate constants for absorption and stimulated emission $(\mathrm{g}=1)$ 
3. Identical partition coefficients in the upper and lower levels of the transition (all $\delta_{i}$ are equal).

These constraints are later removed in the numerical models.

The states and processes in the coupled relaxation model are those shown in Fig. 1. The system can be described by using six coupled firstorder differential equations with constant coefficients

$$
\frac{\mathrm{dC}_{\mathrm{k}}}{\mathrm{dt}}=\sum_{\mathrm{n}=1}^{6} \mathrm{~K}_{\mathrm{kn}} \mathrm{C}_{\mathrm{n}} \quad \mathrm{k}=1-6
$$

where $C_{n}$ is the concentration in the $n^{\text {th }}$ state, and $K_{k n}$ 's are given by Eqs. (1-6). If the initial concentrations (before the laser pulse) of the states are in equilibrium,

$$
C\left(R_{i} T_{i}\right)=\left[\frac{\alpha}{1-\alpha}\right] C\left(R_{i} T_{j}\right) \quad \text { and } \quad C\left(R_{i} T_{i}\right)=\left[\frac{\alpha \delta}{1-\delta}\right] C\left(R_{j}\right)
$$

for both rotational manifolds. Then, during the laser pulse

$$
\frac{d C\left(R_{i}^{\ell} T_{i}\right)}{d t}=-\frac{d C\left(R_{i}^{u} T_{i}\right)}{d t}, \frac{d C\left(R_{i}^{\ell} I^{\prime \prime}\right)}{d t}=-\frac{d C\left(R_{i}^{u} \cdot T_{j}\right)}{d t}
$$

and

$$
\frac{d C\left(R_{j}^{\ell}\right)}{d t}=-\frac{d C\left(R_{j}^{u}\right)}{d t}
$$

The six equations can thus be reduced to three that involve concentrations of only one rotational manifold. Since these three equations are still of the form given in Eq. (7), the solutions are given by

$$
C_{K}=C_{K}^{0}+\sum_{n=1}^{3} B_{K n} e^{D_{n}^{t}} \quad K=1-3
$$


where $C_{K}^{0}, B_{K n}$, and $D_{n}$ are constants. The evaluation of the constants is given in Appendix C. The amount of absorption is then

$$
A_{R T}(t)=\frac{1}{A_{S}} \sum_{K=1}^{3}\left|C_{K}(t)-C_{K}(0)\right|
$$

where $A_{S}$ is the absorption when the transition is completely saturated.

In the rotational relaxation model, translational equilibrium is assumed, and the $R_{i}^{m} T_{i}$ and $R_{i}^{m} T_{j}$ states are combined into a single $R_{i}^{m}$ state, $m=u, 1$. Processes 2 through 4, 6, and 8 are removed; only one absorption and two rotational relaxation processes remain. A system that is initially at equilibrium can then be described by two equations

$$
\frac{\mathrm{dC}_{\mathrm{k}}^{\prime}}{\mathrm{dt}}=\mathrm{K}_{\mathrm{k} 1} \cdot \mathrm{C}_{1}^{\prime}+\mathrm{K}_{\mathrm{k} 2} \mathrm{C}_{2}^{\prime} \quad \mathrm{k}=1,2
$$

The solutions are of the form.

$$
C_{K}^{\prime}=C_{K}^{\prime 0}+K_{K 1}^{\prime} e^{D_{1}^{\prime} t}+B_{K 2}^{\prime} e^{D_{2}^{\prime} t} \quad K=1,2
$$

where the constants are evaluated in Appendix IV.

The amount absorbed is

$$
A_{R}(t)=\frac{1}{A_{s}}\left[\left|C_{1}^{\prime}(t)-C_{1}^{\prime}(0)\right|+\left|C_{2}^{\prime}(t)-C_{2}^{\prime}(0)\right|\right]
$$

In the equilibrium model, both rotational and transiational equilibrium are assumed. This model has only two states (one representing each manifold) and one process (absorption process 1). The amount of absorption is given by 


$$
A_{E}=B^{0}\left[1-\exp \left(-D^{0}\right)\right]
$$

where $B^{0}$ includes normalization by $A_{S} \cdot$ Evaluation of $B^{0}$ and $D^{0}$ is also given in Appendix D.

\section{NUMERICAL MODELS}

The numerical models are used to determine the effects of removing the three constraints imposed on the analytical models. The system can be described by six simultaneous differential equations in the form of Eq. (7) with the additional complication of time varying coefficients. Since a general analytical solution could not be found, the equations were solved numerically by using a modification of the NEST computer program. ${ }^{7,8}$ The amount of absorption from the finite relaxation models is then compared with that from the equilibrium model.

\section{E. ENRICHMENT MODELS}

The enrichment models incorporate coupled rotational-translational relaxation into a model of the two-step photodissociation method of isotope en richment. This method includes isotopically selective first-step infrared excitation, second-step ultraviolet photodissociation, vibrational energy transfer processes, and chemical reactions. The particular system modeled is $\mathrm{HBr}-\mathrm{NO}$, where $\mathrm{H}^{79} \mathrm{Br}$ is vibrationally excited to the $\mathrm{v}=1$ vibrational level by a single-line resonance laser, and an intense ultraviolet source dissociates vibrationally excited HBr. The bromine atoms are then scavenged with NO to form the isotopically enriched stable product BrNO. Construction of the equilibrium model is described by Hwang, Kamada, and Badcock ${ }^{9}$ in a separate paper.

In the finite relaxation model, the $\mathrm{H}^{79} \mathrm{Br}(\mathrm{v}=0)$ and $\mathrm{H}^{79} \mathrm{Br}(\mathrm{v}=1)$ levels are each divided into the sublevels shown in Fig. 1. The rotational relaxation rates constants are calculated from line-broadening data ${ }^{10,11}$ under the assumption that only rotational and translational relaxation collisions are responsible for line broadening. The $K_{L}$ values are calculated with the same line-broadening data. The rate constants for ultraviolet photodissociation are independent of the rotational-translational state. 
For kinetic processes (other than rotational relaxation) that involve $\mathrm{H}^{79} \mathrm{Br}(\mathrm{v}=0)$ or $\mathrm{H}^{79} \mathrm{Br}(\mathrm{v}=1)$ as a product in the equilibrium model, the rate constant at rotational equilibrium $\mathrm{K}_{\mathrm{E}}$ is parcelled as follows:

1. $\alpha \delta \mathrm{K}_{E}$ for $\mathrm{R}_{\mathrm{i}} \mathrm{T}_{\mathrm{i}}$ as product

2. $\sigma(1-\alpha) K_{E}$ for $R_{i} T_{j}$ as product

3. $(1-\delta) \mathrm{K}_{E}$ for $\mathrm{R}_{\mathrm{j}}$ as product.

For reactions with two rotational-translational states as products, the same parcelling process was used for the nine different combination of products.

A set of base conditions is used to facilitate comparison of results upon variation of conditions. The base absorption and kinetic parameters used are given in Appendix E. Unless specified, base conditions were used.

The enrichment is measured by two criteria: enrichment ratio and isotopic product difference. The enrichment ratio $\beta$ is defined by $\left(E \times R^{0}\right) /$ $\left(E^{0} \times R\right)$, where $E$ and $R$ are the number of atoms in the products per unit volume of the enriched isotope and.all other isotopes, respectively. $E^{0}$ and $R^{0}$ are the initial abundances of the enriched isotope and all other isotopes, respectively. The enrichment ratio is a measure of increase in isotope ratio of products, and its values range from one (no enrichment) to infinity (complete enrichment). The isotopic product difference $\gamma$ is defined by $\left(E / E^{0}\right)-$ $\left(R / R^{0}\right)$. It is a measure of quantity of enriched products and has units of concentration. 


\section{RESULTS}

\section{A. ANALYTICAL MODELS}

The effects of rotational relaxation on single-line laser absorption are governed by the rotational relaxation rate constant; rotational partition coefficient; laser pulsewidth; absorption rate constant; and, to some extent, the translational relaxation rate constant. The effects of varying the rotational relaxation and absorption rate constants are shown in Fig. 2. For a constant $K_{R}$ value, $A_{R T}$ increases linearly with $K_{L}$ for low $K_{L}$ values and approaches an asymptote for high $K_{L}$ values. For $A_{R T} \ll 1$, the asymptotic behavior is caused by the rotational bottleneck, whereas saturation of the transition (optical bleaching) causes the asymptotic approach for $A_{R T}$ near unity. For low $K_{r}$ values $\left(<5 \times 10^{4}\right), A_{R T}$ is not a large function of $K_{R}$ because the amount of absorption is too small to either strongly perturb the distribution of the lower manifold or significantly populate the upper manifold. For larger $K_{r}$ (and hence $A_{R T}$ ), the dependence of $A_{R T}$ on $K_{R}$ increases until saturation effects are significant. The $A_{R T}$ values for other conditions can be calculated from the equations given in Appendix $C$.

The minimum rotational relaxation rate constant needed to maintain equilibrium $K_{R}^{*}$ was also calculated, where equilibrium was assumed whenever $A_{R T} / A_{E} \geq 0.9$. The $K_{R}^{*}$ value, which is a function of total pressure, is an indication of the optimum total pressure for state-selected chemistry. A lower pressure and $K_{R}$ value would produce the bottleneck effect and limit absorption. A higher pressure and $K_{R}$ value would increase the rate of energy transfer collisions that destroy state selectivity without increasing absorption.

The $K_{R}^{*}$ value as a function of laser pulsewidth $t$ and $K_{L}$ is shown in Fig. 3. For a particular $t$, as $K_{L}$ is increased, $K_{R}^{*}$ increases rapidly at first, peaks, decreases slightly, and then reaches an asymptote. The original rapid increase is caused by the rapid increase in the amount of 


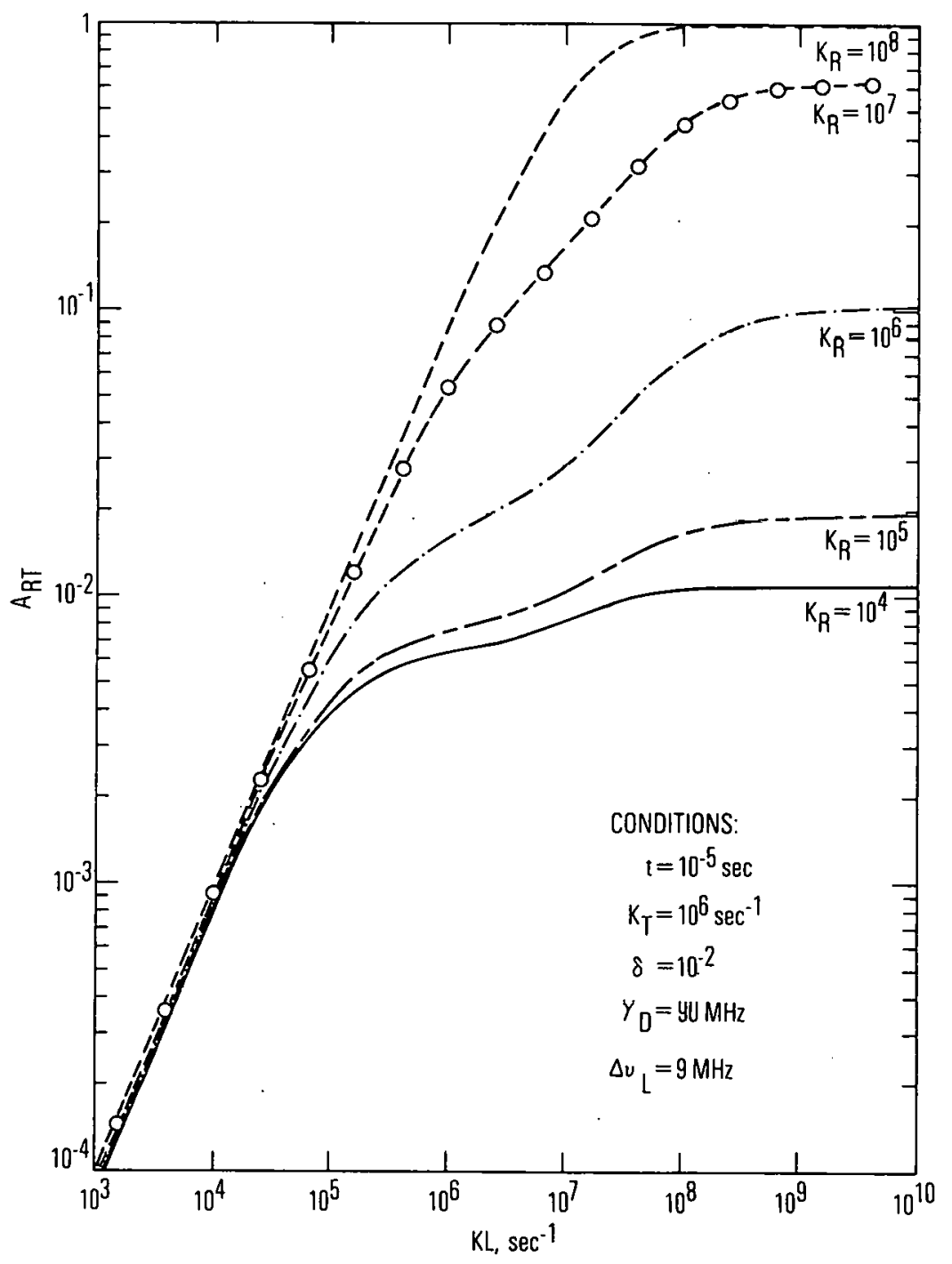

Figure 2. Variation of Rotational

Relaxation Rate 


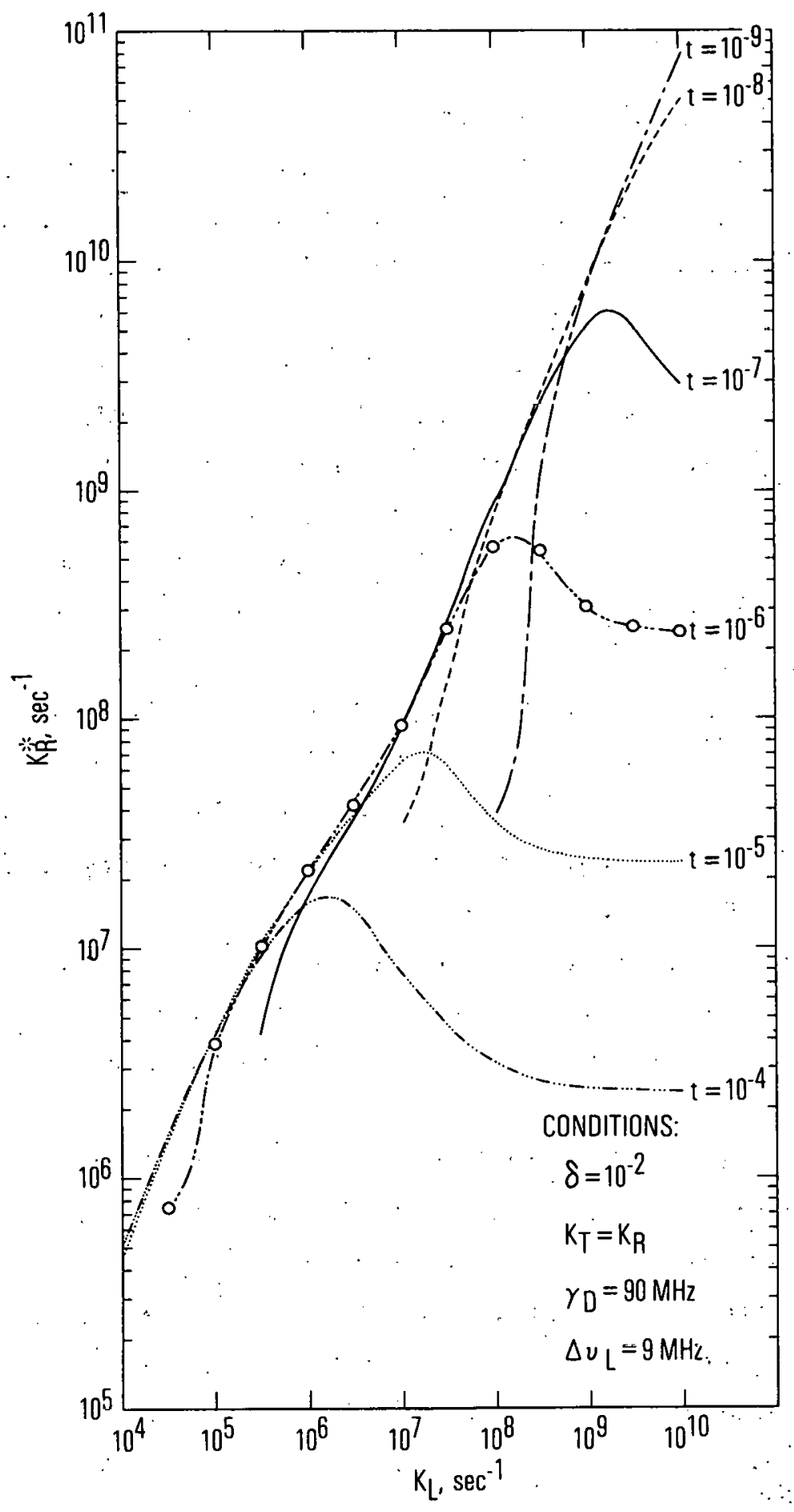

Figure 3. Variation of Laser Pulsewidth 
absorption. The peaking and decrease are caused by larger saturation effects in the equilibrium model. This decreasing region is the saturation region, and the asymptotic value is approached as complete saturation is approached in both the finite relaxation and equilibrium models.

When pulse duration is increased by a factor of 10 , both the asymptotic $K_{R}^{*}$ value and the $K_{L}$ value at the $K_{R}^{*}$ peak decrease by approximately a factor of 10 . Thus, the asymptotic $K_{R}^{*} t$ value is 230 , and $K_{R}$ peaks at $K_{2} t=180$ for all $t$. For $K_{L}$ values below saturation, the slope of the curves becomes greater as $\mathrm{t}$ is decreased. For very low $\mathrm{K}_{\mathrm{L}}$ values, no relaxation is required because the amount of absorption is too small. This $\mathrm{K}_{\mathrm{L}}$ region, marked by the absence of curves, occurs at increasing $K_{L}$ values with shorter pulse durations.

Variation of the rotation partition coefficient $\delta$ yields results similar to those obtained with variation of $t$ (Fig. 4). Thus, $K_{R}^{*}$ peaks at $\delta K_{L} t=1.8$, and the asymptotic $6 \mathrm{~K}_{\mathrm{R}}$ t value is 2.3 for all $\mathrm{t}$ and $\delta$. Before the saturation region, the slope of the curves for lower $\delta^{\prime} s$ is larger because the $K_{R}^{*}$ values are independent of $K_{L}$ for $K_{L}<10^{6} \mathrm{sec}^{-1}$.

Variation of the translational relaxation rate $\mathrm{K}_{\mathrm{T}}$ makes no difference in the saturation region (Fig. 5). Before that region, translational relaxation does lower the necessary rotational rate, and the lowering is greater as $\mathrm{K}_{\mathrm{L}}$ decreases.

In order to determine when translational equilibrium is a valid assumption, the absorption from the rotational-translational model $A_{R T}$ is compared with that from the rotational model $A_{R}$. An example is given in Fig. 6, where the $A_{R T} / A_{R}$ ratio is plotted as a function of $K_{L}$. The ratio is close to unity for low $K_{L}$ values because the absorption level is low. At moderate $K_{L}$ values, the ratio decreases rapidly because neither $K_{R}$ nor $K_{T}$ is high enough to maintain equilibrium. At high $K_{L}$ values, saturation effects for process 1 increase the ratio.

In general, translational equilibrium can be assumed ( $\left.A_{R T} / A_{R} \geq 0.9\right)$ whenever $K_{T}$ or $K_{R} \geq 10^{8} \sec ^{-1}, K_{L} t<2 \times 10^{-3}$, or $K_{L} t>3 \times 10^{4} \cdot A$ 


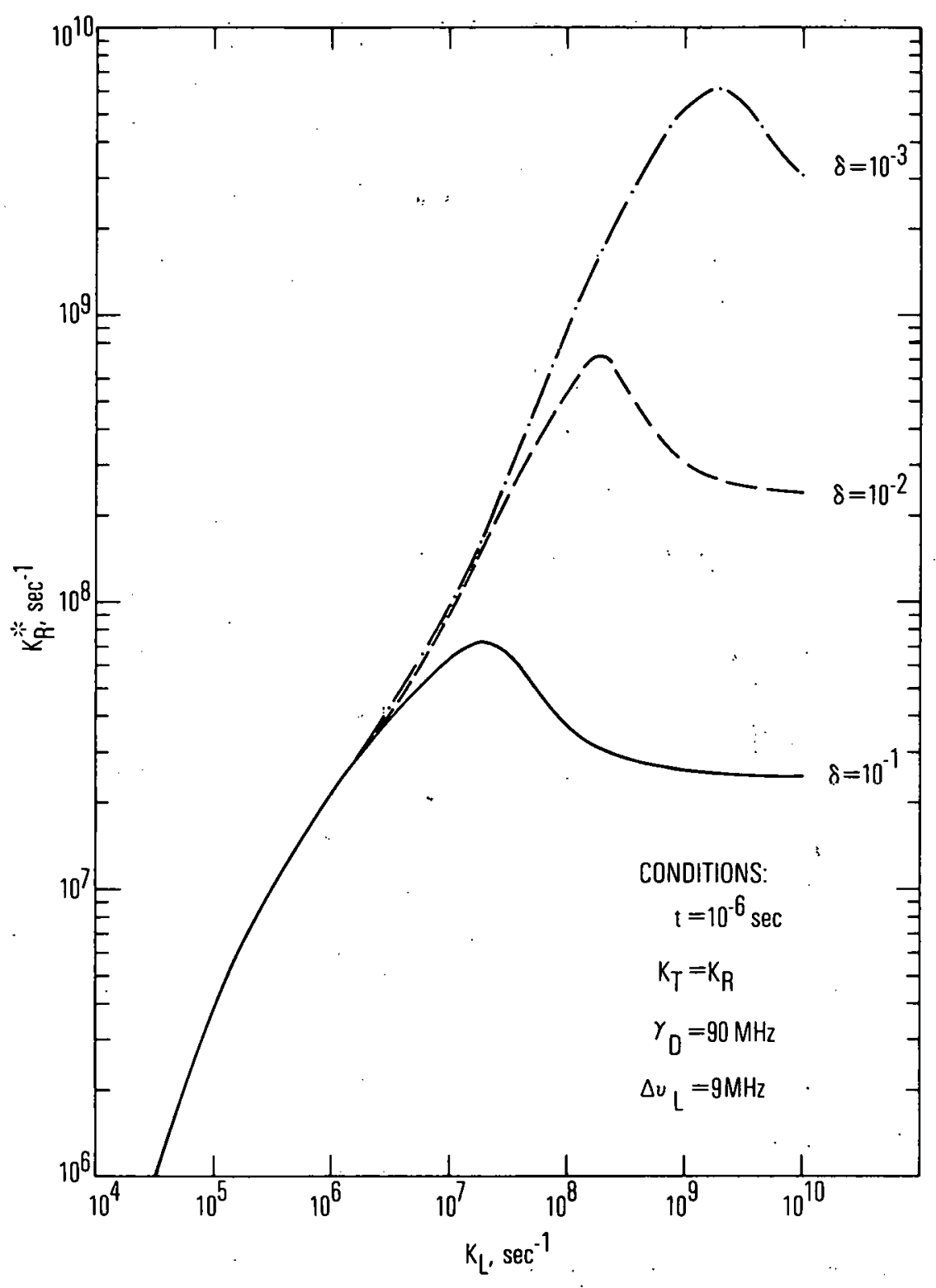

Figure 4. Variation of Rotational Partition Coefficients 


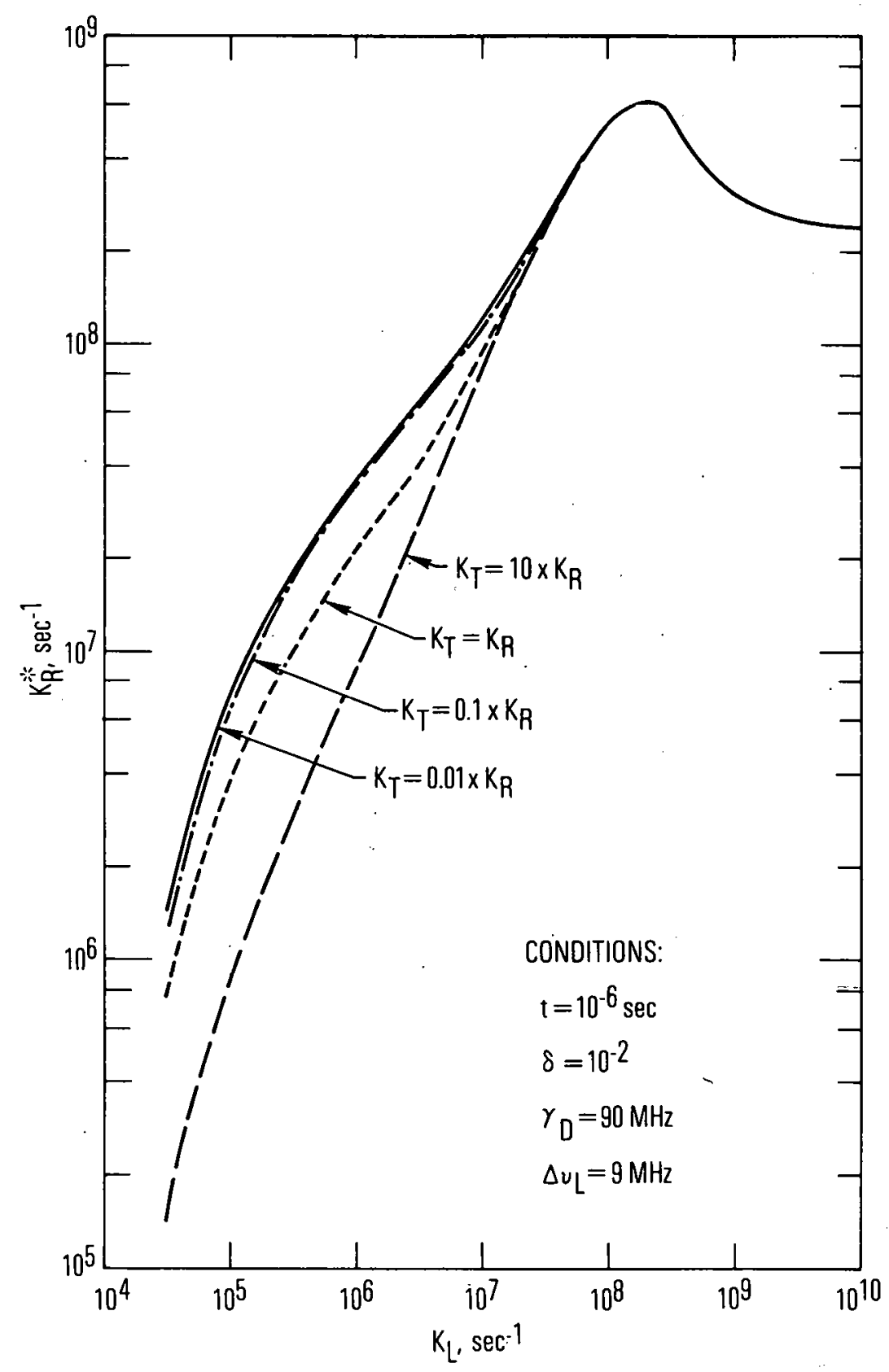

Figure 5. Variation of Translational Relaxation Rate 


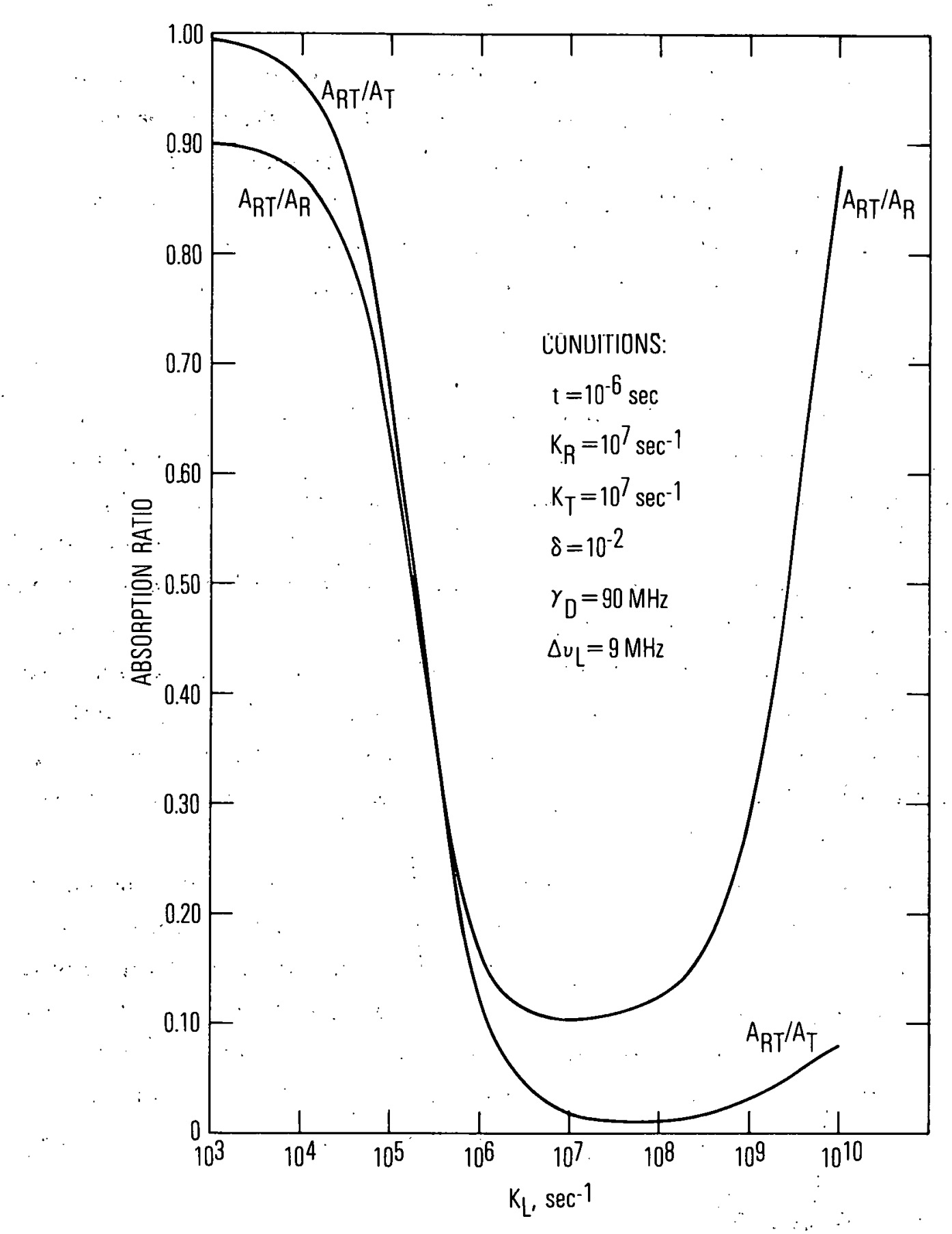

Figure 6. Rotational Model and Translational Model 
relaxation rate constant of $10^{8} \mathrm{sec}^{-1}$ is sufficient to produce essentially a Lorentz-broadened line. Since a Lorentzin, pressure-broadened line is considered homogeneous, hole burning can not oc'cur. For $K_{L} t<2 \times 10^{-3}$, absorption is so small that equilibrium is not significantly perturbed. For $\mathrm{K}_{\mathrm{L}} \mathrm{t}>3 \times 10^{4}$, saturation effects promote translational equilibrium. For other conditions, the equations in Appendixes $C$ and $D$ must be used for determination of $A_{R T} / A_{R}$.

B. NUMERICAL MODELS

The numerical models.were used to study the effects of removing the three constraints imposed on the analytical models. The results obtained upon variation of pulseshapes with constant pulse energies are shown in Fig. 7. The absorption as a function of $K_{R}$ behaves similarly for Gaussian, 12 triangular, and rectangular pulses. For maintenance of rotational equilibrium, a Gaussian pulse requires the lowest $K_{R}$, whereas the rectangular pulse requires the highest. For equal halfwidths, the Gaussian pulse has the longest base and the rectangular pulse has the shortest. Thus, the $K_{R}^{*}$ values calculated in the analytic models are upper bounds. The differences, however, are not expected to be large inasmuch as the $K_{R}$ range at a particular absorption in Fig, 7 i.s always less than a factor of 2.5 .

The effects of varying $g$ and the ratio of upper - to lower-level partition coefficients are shown in Table $I$. The worst case was taken for $\Delta J= \pm 1,0$ transitions by setting $g=1 / 3$ and the $\delta^{\mathrm{u}} / \delta^{\ell}$ ratio $=3$. Most transitions would have values closer to unity, the conditions of the analytical models. The results are within $2 \%$ of the analytical results except at the highest $K_{L}$ value used (which is in the asymptotic region), where there is $17.5 \%$ deviation. Thus, the analytical results should be valid for most values of b or the $\delta_{u} / \delta_{\ell}$ ratio.

C. ENRICHMENT MODELS

The enrichment models were used to study the effects of rotational relaxation on the enrichment produced by the two-step photodissociative system of $\mathrm{HBr}$ and NO. Results for various pressures, laser intensities, and 


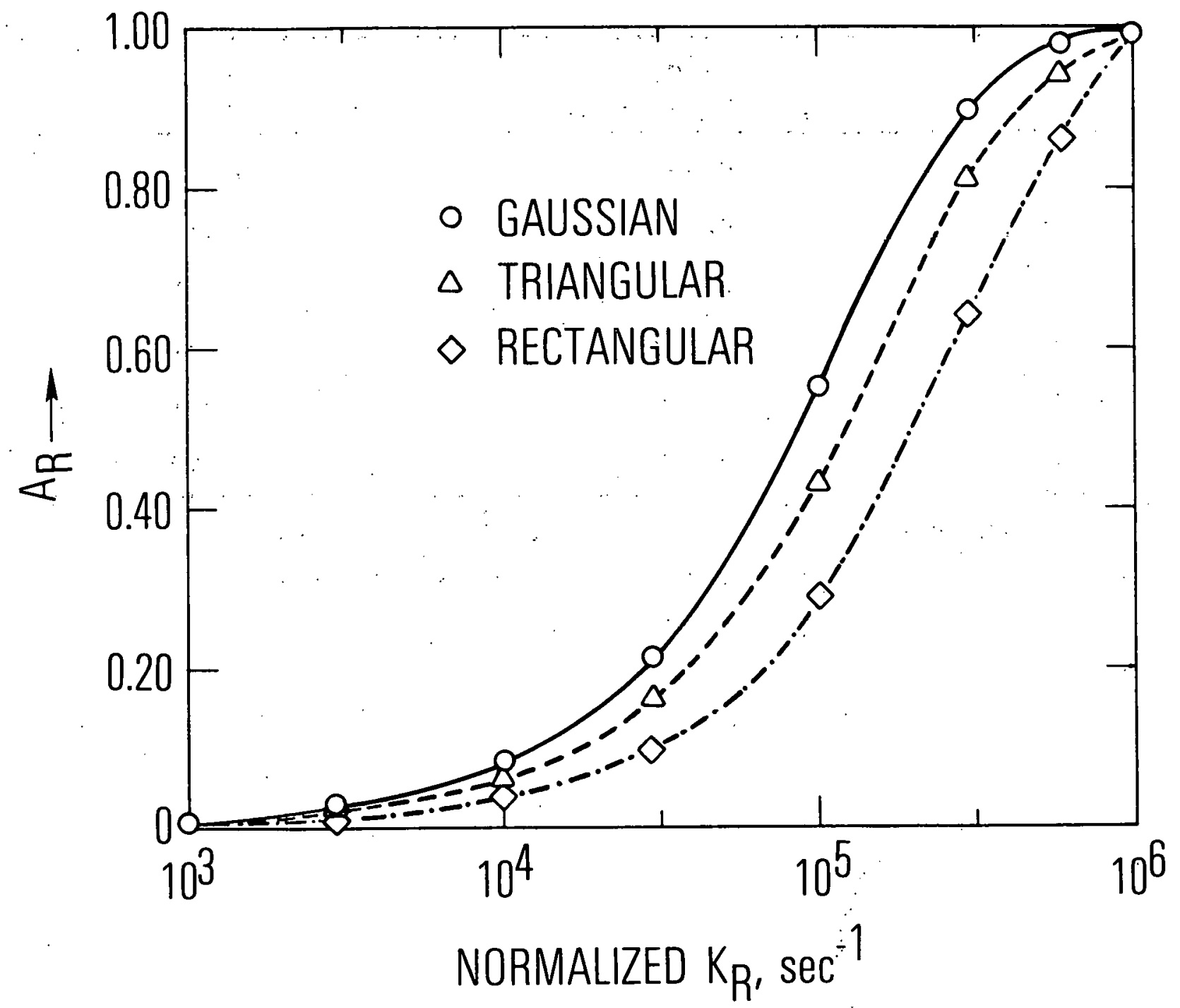

Figure 7. Variation of Pulse Shape 
Table I. Variation of Degeneracy Ratio and Delta ${ }^{a}$

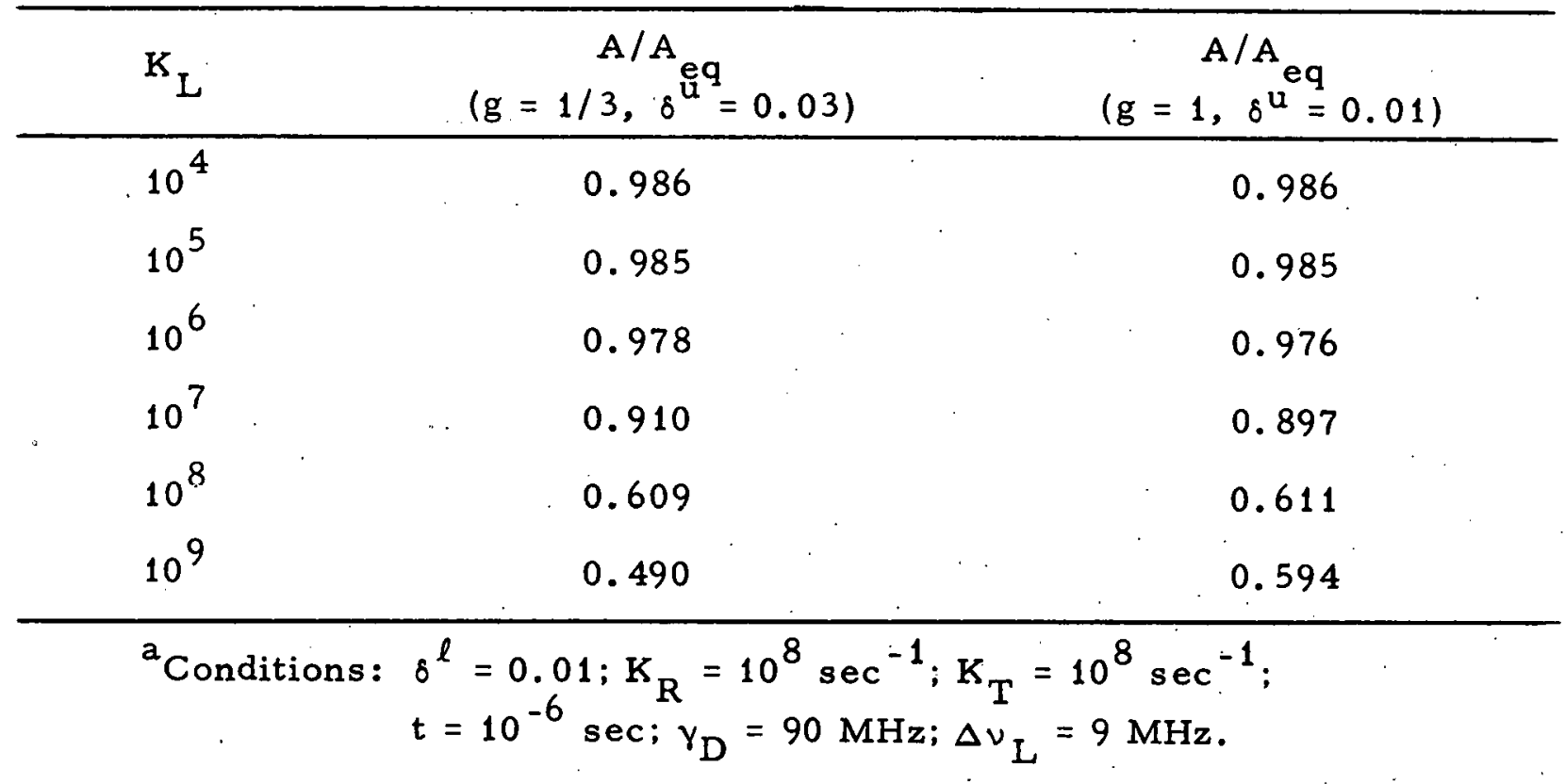


rotational relaxation rate constants are shown in Table II. The enrichment of the finite relaxation model is compared with that of the equilibrium model (with subscript eq). Differences of less than $1 \%$ a re not significant because of the estimated uncertainties in $\beta$ and $\gamma$.

For base conditions, inclusion of rotational relaxation does not alter enrichment. For lower initial pressures and relaxation rate constants, the ratio $\gamma / \gamma_{\text {eq }}$ is about the same as the $A / A_{\text {eq }}$ ratio, whereas the changes in $B / \beta_{\text {eq }}$ are smaller. The results are somewhat different for the strongly saturating condition when the pulse energy is increased to $7.5 \mathrm{~mJ}$. The $B / \beta_{\text {eq }}$ and $\gamma / \gamma_{\text {eq }}$ ratios are smaller than the $A / A_{\text {eq }}$ ratio. In this case; greater absorption in the first part of the laser pulse in the equilibrium model produces higher enrichment of $\mathrm{H}^{79} \mathrm{Br}$ since the re is less isotopic energy transfer.

Thus, although inclusion of rotational-relaxation processes does not alter enrichment for base conditions, it can promote significant differences for lower pressures, slower relaxation rate constants; or higher laser energies. In addition, rotational relaxation can have a greater effect on enrichment than on absorption for strongly saturating conditions.

D. COUPLING OF MODELS AND EXPERIMENTS

The models can be used to determine the range of proper experimental conditions and the optimization of conditions. As an example, the absorption calculated in the analytical models as a function of laser pulse duration for constant energy pulses is given in Table III. The inputs are for the HBr-NO two-step photodissociation enrichment system with 50 Torr NO and 4 Tor $\mathrm{HBr}$ at $300 \mathrm{~K}$ and $\mathrm{a} 1.5 \mathrm{~mJ}$.pulse. The results indicate that a rotational bottleneck will not result for pulse durations greater than $30 \mu \mathrm{sec}$.

Another example is given in Table IV, where the analytical model absorptions are calculated as a function of pressure and laser energy. The inputs are for the HBr.+ I vibrational photochemistry system with initial concentrations of 0.25 Torr HBr, $0.3 \operatorname{Torr~}_{2}$, and a variable amount of inert buffer Ar. The $\mathrm{K}_{\mathrm{L}}$ value of $3.4 \times 10^{5} \mathrm{sec}^{-1}$ corresponds to a $1.5 \mathrm{~mJ} \mathrm{P}_{1}(5)$ $\mathrm{HBr}$ single-line laser pulse. The, results indicate that 20 Torr Ar is sufficient to produce an $A / A_{\text {eq }}$ ratio $\geq 0.9$ for laser pulse energies up to $9.5 \mathrm{~mJ}$. 
Table II. Results of Enrichment Models

\begin{tabular}{|c|c|c|c|c|c|}
\hline \multirow[b]{2}{*}{ Conditions } & \multicolumn{2}{|c|}{$\underline{\text { Relaxation Model }}$} & \multirow[b]{2}{*}{$\frac{\beta}{\beta \text { eq }}$} & \multirow[b]{2}{*}{$\frac{\gamma}{\gamma_{e q}}$} & \multirow[b]{2}{*}{$\frac{A}{A_{e q}}$} \\
\hline & $\beta$ & $\begin{array}{c}\gamma \times 10^{-13} \\
\text { molecules } / \\
\mathrm{cm}^{3}\end{array}$ & & & \\
\hline $\begin{array}{l}\text { Base conditions: } 50 \text { Torr NO; } 4 \text { Torr HBr; } \\
1.5 \mathrm{~mJ} \text { laser pulse; } \mathrm{K}_{\mathrm{R}}=9.3 \times 10^{-10} \text { and } \\
3.7 \times 10^{-10} \mathrm{~cm}^{3} / \text { molecule-sec for } \mathrm{HBr}- \\
\mathrm{HBr} \text { and } \mathrm{HBr}-\mathrm{NO} \text { collisions, respectively. }\end{array}$ & 1.87 & 1.63 & 1.00 & 1.00 & 1.00 \\
\hline 10 Torr NO, 0.5 Torr HBr & 1.78 & 0.451 & 0.995 & 0.955 & 0.975 \\
\hline 1. 5 Torr NO, 1 Torr $\mathrm{HBr}$ & 1.03 & 0.401 & 1.00 & 0.86 & 0.865 \\
\hline $\begin{array}{l}\mathrm{K}_{\mathrm{R}}^{\prime}=1.85 \times 10^{-10} \text { and } 7.4 \times 10^{-11} \\
\mathrm{~cm}^{3} / \text { molecule-sec for } \mathrm{HBr}-\mathrm{HBr} \text { and }\end{array}$ & 1.87 & 1.59 & 1.00 & 0.98 & 0.985 \\
\hline $\begin{array}{l}\mathrm{HBr}-\mathrm{NO} \text { collisions, respectively. } \\
\mathrm{K}_{\mathrm{R}}^{\prime}=4.65 \times 10^{-11} \text { and } 1.85 \times 10^{-11} \\
\mathrm{~cm}^{3} / \text { molecule }-\mathrm{sec} \text { for } \mathrm{HBr}-\mathrm{HBr} \text { and }\end{array}$ & 1.85 & 1.51 & 0.99 & 0.93 & 0.94 \\
\hline HBr-NO collisions, respectively. & & & & & \\
\hline $7.5 \mathrm{~mJ}$ laser pulse & 2.07 & 5.87 & 0.985 & 0.90 & 0.995 \\
\hline
\end{tabular}


Table III. HBr Absorption for Mixtures of $\mathrm{HBr}$ and $\mathrm{NO}^{\mathrm{a}}$

\begin{tabular}{lccc}
\hline $\mathrm{K}_{\mathrm{L}}, \mathrm{sec}^{-1}$ & $\mathrm{t}, \mu \mathrm{sec}$ & $\mathrm{A} / \mathrm{A}$ eq \\
\hline $2.15 \times 10^{5}$ & $\ddots 1000$ & 0.999 \\
$7.2 \times 10^{5}$, & 300 & 0.997 \\
$2.15 \times 10^{6}$ & $\because$ & 100 & 0.991 \\
$7.2 \times 10^{6}$ & $\ddots$ & 30 & 0.972 \\
$2.15 \times 10^{7}$ & & 3 & 0.844 \\
$2.15 \times 10^{8}$ & & 1 & 0.780 \\
\hline
\end{tabular}

${ }^{\mathrm{a}}$ Conditions: $\delta=0.14 ; \mathrm{K}_{\mathrm{R}}=7.2 \times 10^{8} \mathrm{sec}^{-1} ; \mathrm{K}_{\mathrm{T}}=4.0 \times 10^{7}$ $\mathrm{sec}^{-1} ; \gamma_{\mathrm{D}}=50.7 \mathrm{MHz} ; \Delta \gamma_{\mathrm{L}}=5.07 \mathrm{MHz}$; $\beta=0.818182$. 
Table IV. HBr Absorption for Mixtures of $\mathrm{HBr}, \mathrm{I}_{2}$, and $\mathrm{Ar}^{\mathrm{a}}$

\begin{tabular}{lcccc}
\hline $\mathrm{K}_{\mathrm{L}}, \mathrm{sec}^{-1}$ & $\mathrm{Ar}, \operatorname{Torr}$ & $\mathrm{K}_{\mathrm{R}}, \mathrm{sec}^{-1}$ & $\mathrm{~K}_{\mathrm{T}}, \mathrm{sec}^{-1}$ & $\mathrm{~A} / \mathrm{A}_{\mathrm{eq}}$ \\
\hline $3.4 \times 10^{5}$ & 20 & $5.2 \times 10^{7}$ & $1.1 \times 10^{8}$ & 0.954 \\
$3.4 \times 10^{5}$ & 10 & $3.0 \times 10^{7}$ & $5.5 \times 10^{7}$ & 0.923 \\
$3.4 \times 10^{5}$ & 5 & $1.9 \times 10^{7}$ & $2.8 \times 10^{7}$ & 0.875 \\
$3.4 \times 10^{5}$ & 2 & $1.25 \times 10^{7}$ & $1.25 \times 10^{7}$ & 0.815 \\
$3.4 \times 10^{5}$ & 0 & $8 \times 10^{6}$ & $1.7 \times 10^{6}$ & 0.739 \\
$8.55 \times 10^{5}$ & 20 & $5.2 \times 10^{7}$ & $1.1 \times 10^{8}$ & 0.945 \\
$2.15 \times 10^{6}$ & 20 & $3.0 \times 10^{7}$ & $1.1 \times 10^{8}$ & 0.915 \\
$5.4 \times 10^{6}$ & 20 & $1.9 \times 10^{7}$ & $1.1 \times 10^{8}$ & 0.862 \\
$1.35 \times 10^{7}$ & 20 & $1.25 \times 10^{7}$ & $1.1 \times 10^{8}$ & 0.807 \\
$3.4 \times 10^{7}$ & 20 & $8 \times 10^{6}$ & $1.1 \times 10^{8}$ & 0.812 \\
\hline
\end{tabular}

${ }^{a}$ Conditions: $\delta=0.14 ; t=6 \times 10^{-7} \mathrm{sec} ; \gamma_{D}=50.7 \mathrm{MHz} ; \Delta \gamma_{L}=$ $5.07 \mathrm{MHz:} \beta=0.818182$. 
The models can also be coupled with absorption experiments to determine rotational relaxation rate constants. The amount of absorption can be a sensitive measure of the rotational relaxation rate, as shown in Table V. A factor of 2 difference in $\mathrm{K}_{\mathrm{R}}$. can result in. 35 to $50 \%$ variation in the amount of absorption. For pressures (and thus $K_{R}$ or. $K_{T}$ values) high enough to approximate homogeneous broadening, absorption is also independent of the laser linewidth and other translational relaxation parameters. Thus, single-line laser absorption experiments coupled with modeling should yield rotational relaxation rate constants and their $\mathrm{J}$-dependence. Although this type of experiment yields results directly related to relaxation of rotational states, it requires neither transient detection of the rapid relaxation process nor a very high resolution spectrometer. The laser linewidth can also be determined with an adequate translational relaxation model by operating under inhomobeneous broadening conditions: 
Table V. Sensitivity of Absorption to Rotational Relaxation Rate ${ }^{a}$

\begin{tabular}{|c|c|c|}
\hline$K_{R}, \sec ^{-11}$ & $\Delta \gamma, \mathrm{MHz}$ & $\mathrm{A}_{\mathrm{RT}}$ \\
\hline $4 \times 10^{7}$ & 9.0 & 0.667 \\
\hline $2 \times 10^{7}$ & 9.0 & 0.453 \\
\hline $1 \times 10^{7}$ & 9.0 & 0.296 \\
\hline $5 \times 10^{6}$ & 9.0 & 0.200 \\
\hline $2.5 \times 10^{6}$ & 9.0 & 0.147 \\
\hline $4 \times 10^{7}$ & 0.9 & 0.680 \\
\hline $4 \times 10^{7}$ & 2.7 & 0.677 \\
\hline $4 \times 10^{7}$ & 27.0 & 0.645 \\
\hline
\end{tabular}




\section{SUMMARY}

Models of rotational and translational relaxation and single-line pulsed absorption were constructed. General analytical solutions that yield the amount of absorption were derived for simple models. The relaxation rates necessary to maintain rotational equilibrium and the conditions necessary to maintain translation equilibrium were calculated for a variety of cases.

More complex models that require numerical solutions were constructed in order to test the validity of the simpler analytical models and to investigate the effects of rotational relaxation on a particular laser isotope enrichment system. The analytical models appear valid for most conditions where self relaxation is not dominant. Rotational equilibration is essentially maintained for the optimum pressure and laser intensity conditions for the HBr-NO twostep dissociation enrichment system. For different conditions or a different system, a rotational bottleneck can definitely limit enrichment.

The results of the analytical models were applied in determining the range of experimental conditions and the optimum conditions to prevent rotational bottlenecks for two experimental systems. The models can also be coupled with absorption experiments to yield rotational relaxation rate constants and their J-dependence. 


\section{A. CALCULATION OF TRANSLATIONAL FRACTION $\alpha$}

Alpha is the fraction of molecules that have the proper velocity component to interact with the radiation in the low pressure limit. For a Gaussian absorption curve and a narrow rectangular resonance laser radiation

$$
\alpha=\operatorname{Erf} \frac{\Delta \nu_{L}}{\gamma_{D}} \sqrt{\ln 2} \quad \nu_{L}<\gamma_{D}
$$

where Erf is the error function, $\Delta \nu_{L}$ is the laser linewidth (HWHM), and $Y_{D}$ is the Gaussian linewidth (HWMH).

B. CALCULATION OF TRANSLATIONAL ABSORPTION

COEFFICIENT $X$

Gamma is the absorption coefficient for the $T_{. j}$ : state relative to that for the $T_{i}$ state.

$$
\begin{aligned}
& \gamma=\frac{(1-f)(\alpha)}{(1-\alpha)(f)} \\
& f=\frac{\int_{0}^{\Delta \nu_{L}}\left\{\frac{\exp -\left[\ln 2 \frac{\Delta \nu}{\gamma_{D}}\right]^{2}}{\left(\frac{2 \pi \Delta \nu}{K_{R}+K_{T}}\right)^{2}+1} d \Delta \nu\right.}{\left\{\frac{\exp -\left[\ln 2 \frac{\Delta \nu}{\gamma_{D}}\right]^{2}}{\left(\frac{2 \pi \Delta \nu}{K_{R}+K_{T}}\right)^{2}+1} d \Delta v\right.} d .
\end{aligned}
$$

These integrals are solved numerically. 


\section{APPENDIX B. COUPLING OF TRANSLATIONAL AND \\ ROTATIONAL RELAXATION}

Translational relaxation will be coupled to rotational relaxation if the change in velocity due to a rotational relaxation collision is sufficient to move a molecule into or out of the linewidth of the laser. The case for the HBr system is considered here.

The linewidth of the $\mathrm{HB} r$ lase $r$ has not been measured. It is estimated to be $3 \mathrm{MHz}$ (FWHM), the same as measured for the HB laser. ${ }^{13}$ The Doppler shift is given by

$$
\nu=\nu_{0}\left(1 \pm \frac{V}{C}\right)
$$

where $\mathrm{V}$ is the molecular velocity, $\mathrm{C}$ is the speed of light, and $\nu_{0}$ is the original frequency.

$$
\begin{aligned}
\text { For the } \mathrm{H}^{79} \operatorname{Br}_{1}(5) \text { line, } \nu_{0}=2451.7 \mathrm{~cm}^{-1} \\
\left|\nu-\nu_{0}\right|=\nu_{0}\left(\frac{\mathrm{V}}{\mathrm{C}}\right)=3 \times 10^{6}=(2451.7 \mathrm{c})\left(\frac{\mathrm{V}}{\mathrm{C}}\right) \quad \cdots \\
\mathrm{V}=1.224 \times 10^{3} \mathrm{~cm} / \mathrm{s} \mathrm{ec} \\
\frac{1}{2} \mathrm{mV}^{2}=\left(5 \times 10^{-1}\right)\left(8 \times 10^{1}\right)\left(1.224 \times 10^{3}\right)^{2}=6 \times 10^{7} \mathrm{erg} / \mathrm{mole}
\end{aligned}
$$

Thus, a shift of $3 \mathrm{MHz}$ would require an energy change of $6 \times 10^{7} \mathrm{erg} / \mathrm{mole}$ along the direction of light propagation.

The minimum energy change associated with a rotational relaxation collision of $\mathrm{HBr}$ is $2 \mathrm{~B}$, where $\mathrm{B}=23.584 \mathrm{cal} / \mathrm{mole}$. The minimum change $2 \mathrm{~B}$ is thus $2 \times 10^{9} \mathrm{erg} / \mathrm{mole}$. Thus, if only $3 \%$ of the minimum energy change is transferred into translation of $\mathrm{HBr}$ in the direction of light propagation, a Doppler shift of $3 \mathrm{MHz}$ will result. 
APPENDIX C. CALCULATION OF A $A_{\text {TT }}$ FOR ROTATIONALTRANSLATIONAL RELAXATION

$$
\begin{aligned}
& A_{R T}=1-A_{0}\left(A_{1} e^{r_{1} t}+A_{2} e^{r_{2} t}+A_{3} e^{r_{3} t}\right) \\
& A_{0}=\frac{1}{D}\left(\frac{1}{1+\alpha}\right) \\
& A_{1}=\left(1+\frac{r_{1}}{K_{R}}\right)\left\{\alpha\left[C_{1}^{2}\left(\delta-C_{2}^{3}\right)+C_{1}^{3}\left(C_{2}^{2}-\delta\right)\right]+C_{2}^{2}\left(C_{1}^{3}-\delta\right)+C_{2}^{3}\left(\delta-C_{1}^{2}\right)\right\} \\
& A_{2}=\left(1+\frac{r_{2}}{K_{R}}\right)\left\{\alpha\left[C_{1}^{3}\left(\delta-C_{2}^{1}\right)+C_{1}^{2}\left(C_{2}^{3}-\delta\right)\right]+C_{2}^{3}\left(C_{1}^{1}-\delta\right)+C_{2}^{1}\left(\delta-C_{1}^{3}\right)\right\} \\
& A_{3}=\left(1+\frac{r_{3}}{K_{R}}\right)\left\{\alpha\left[C_{1}^{1}\left(\delta-C_{2}^{2}\right)+C_{1}^{2}\left(C_{1}^{2}-\delta\right)\right]+C_{2}^{1}\left(C_{1}^{2}-\delta\right)+C_{2}^{2}\left(\delta-C_{1}^{1}\right)\right\}
\end{aligned}
$$

where

$$
\begin{gathered}
D=C_{2}^{1}\left(C_{1}^{2}-C_{1}^{3}\right)+C_{2}^{2}\left(C_{1}^{3}-C_{1}^{1}\right)+C_{2}^{3}\left(C_{1}^{1}-C_{1}^{2}\right) \\
C_{1}^{i}=\frac{K_{R}\left(\frac{\delta}{1-\delta}\right)+K_{T}\left(\delta+\frac{(1+\delta) r_{i}}{K_{R}}\right)}{\left(r_{i}+K_{T}+\gamma K_{L}+\frac{K_{R}}{1+\delta}\right)(1+\alpha)} \quad i=1,2,3 \\
C_{2}^{i}=\frac{\frac{r_{i}}{K_{R}}(1+\delta)\left[\alpha K_{T}+(1+\alpha)\left(K_{R}+\gamma K_{L}+r_{i}\right)\right]+\delta\left[\alpha K_{T}+\frac{K_{R}}{(1+\delta)}+\gamma(1+\alpha) K_{L}\right]}{(1+\alpha)\left(\gamma K_{L}+K_{T}+\frac{K_{R}}{1+\delta}+r_{i}\right)}
\end{gathered}
$$


where

$$
\begin{gathered}
r_{1}=2(-p / 3)^{1 / 2} \cos \left(\frac{a^{\prime}}{3}\right)-\frac{a_{2}}{3} \\
r_{2}=-2(-p / 3)^{1 / 2} \cos \left(\frac{a^{\prime}+\pi}{3}\right)-\frac{a_{2}}{3} \\
: \\
r_{3}=-2(-p / 3)^{1 / 2} \cos \left(\frac{a^{\prime}-\pi}{3}\right)-\frac{a_{2}}{3}
\end{gathered}
$$

where

$$
a^{\prime}=\cos ^{-1}\left[\frac{-q}{2 \sqrt{-(p / 3)^{3}}}\right]
$$

where

$$
\begin{aligned}
& p=-\frac{a_{2}^{2}}{3}+a_{1} \\
& q=2\left(\frac{a_{2}}{3}\right)^{3}-\frac{a_{1} a_{2}}{3}+a_{0}
\end{aligned}
$$

where

$$
\begin{aligned}
& a_{2}=\left(\frac{2+\delta}{1+\delta}\right) K_{R}+K_{T}+(1+\gamma) K_{r} \\
& a_{1}=K_{R}\left[K_{T}+\frac{K_{R}}{1+\delta}\right]+K_{L}\left[\gamma K_{L}+\left(\frac{\alpha+\gamma}{1-\alpha}\right) K_{T}+(1+\delta) K_{R}\right] \\
& a_{0}=\left(\frac{\delta}{1+\delta}\right) K_{L} K_{R}\left[\gamma K_{L}+\left(\frac{\alpha+\gamma}{1+\alpha}\right) K_{T}+\left(\frac{\alpha+\gamma}{1+\alpha}\right)\left(\frac{1}{1+\delta}\right) K_{R}\right]
\end{aligned}
$$




\section{APPENDIX D. CALCULATION OF $A_{R}$ AND $A_{E}$}

A. ROTATIONAL RELAXATION CASE

$$
A_{R}=1-\frac{1}{r_{2}-r_{1}}\left[\left(r_{2}-r_{0}\right) e^{r_{1} t}-\left(r_{1}-r_{0}\right) e^{r_{2} t}\right]
$$

where

$$
\begin{aligned}
& r_{0}=-\left(\frac{\delta}{1+\delta}\right) K_{L}^{\prime} \\
& r_{1}=-\frac{K_{L}^{\prime}}{2}-\frac{K_{R}}{2}+\left[\left(K_{L}^{\prime}+K_{R}\right)^{2}-\frac{4 \delta}{(1+\delta)} K_{R} K_{L}^{\prime}\right]^{1 / 2} \\
& r_{2}=-\frac{1}{2}\left\{K_{L}^{\prime}+K_{R}+\left[\left(K_{L}^{\prime}+K_{R}\right)^{2}-\frac{4 \delta}{(1+\delta)} K_{R} K_{L}^{\prime}\right]^{1 / 2}\right\}
\end{aligned}
$$

B. EQUILIBRIUM CASE

$$
\begin{aligned}
& A_{E}=1-e^{r_{0} t} \\
& r_{0}=-\left(\frac{\delta}{1+\delta}\right) K_{L}^{\prime}
\end{aligned}
$$

where

$$
K_{L}^{\prime}=(\alpha+\gamma-\alpha \gamma) K_{L}
$$




\section{APPENDIX E. INPUTS FOR BASE CONDITIONS OF ENRICHMENT MODELS}

For calculation of $K_{L}$, the following parameters were used:

1. A $1.5 \mathrm{~mJ} \mathrm{H}^{79}{ }_{\mathrm{Br}}\left(\mathrm{P}_{1}(5)\right.$ laser with a Gaussian pulsewidth of $3 \times 10^{-7} \sec$ FWHM

2. Line strength of $191.3 \mathrm{~cm}^{-1} \mathrm{~atm}^{-1(13)}$

3. $\mathrm{HBr}-\mathrm{HBr}$ line-broadening parameter of $9.4 \times 10^{-6}(\mathrm{~T})^{1 / 2} \mathrm{~cm}^{-1}$ $\operatorname{Torr}^{-1(10)}$

4. HBr-NO line-broadening parameter of $5.1 \times 10^{-6}(\mathrm{~T})^{1 / 2} \mathrm{~cm}^{-1}$ Tor $\mathrm{r}^{-1}$, estimated from $\mathrm{HCl}-\mathrm{CO}$ line broadening 11

For calculation of $K_{R}$, the line-broadening parameters given above were used.

For calculation of $\mathrm{K}_{\mathrm{T}}$, a hard sphere diameter of $3.41 \times 10^{-8} \mathrm{~cm}^{14}$ was used with NO pressure $=50$ Torr, HBr pressure $=4$ Torr, tempera ture $=300 \mathrm{~K}, \gamma_{\mathrm{D}}=50.7 \mathrm{MHz}, \Delta \nu_{\mathrm{L}}=5.07 \mathrm{MHz}, \beta=0.818182, \delta^{\mathrm{u}}=0.1489$, and $\delta^{\ell}=0.1309$. 
THIS PAGE

WAS INTENTIONALLY

LEFT BLANK 


\section{REFERENCES}

1. V. S. Letokhov, Science 180, 451 (1973).

2. R. V. Ambartzumian, V. S. Letokhov, G. N. Makarov, and A. A. Puretzky, in Laser Spectroscopy, edited by R. G. Brewer and A. Mooradian (Plenum Press, New York, 1973), p. 611.

3. J. L. Lyman and S. D. Ruckwood, J. Appl. Phys. 47, 595 (1976).

4. J. L. Lyman, R. J. Jensen, J. P. Rink, C. P. Robinson, and S. D. Rockwood, J. Appl. Phys. Lett. 27, 87 (1975).

5. V. S. Letokhov and A. A. Makarov, J. Photochem. 2, 471 (1973).

6. Y. S. Liu, J. Appl. Opt. 13, 2505 (1974).

7. E. B. Turner, G. Emanuel and R. L. Wilkins, The NEST Chemistry Computer Program Volume 1, SAMSO-TR-70-311, Vol. 1, The Aerospace Corp., El Segundo, California (1970).

8. J. F. Holt, DSTIFER The Numerical Integrator Used in the RESALE Relation Oscillation Program, TOR-0074(9320)-4, The Aerospace Corp., E1 Segundo, California (1974).

9. W. C. Hwang, R. F. Kamada, and C. C. Badcock, Int. J. Chem. Kinetics (to be published).

10. W. S. Benedict and R. Herman, J. Quant. Spectrosc. Radiat. Transfer $\underline{3}$, 265 (1963).

11. D. H. Rank, D. P. Eastman, B. S. Rao, and T. A. Wiggins, J. Mol. Spectrosc. 10, 34 (1963).

12. For simplification, the Gaussian pulse was truncated at $\Delta t=3$ halfwidths.

13. B. P. Gustafs on and B. S. Rao, Can. J. Phys. 48, 330 (1970).

14. F. J. Zeleznik and R. A. Svehla, J. Chem. Phys. 53, 632 (1970). 


\section{DISTRIBUTION}

Internal

C. C. Badcock
N. Cohen
R. B. Cohen
S. Feuerstein
R. F. Heidner
R. R. Herm
J. J. T. Hough
W. C. Hwang
B. R. Johnson
P. F. Jones
H. S. Judeikis
J. F. Kalsch
R. F. Kamada

G. W. King

G. C. Light

D. D. Little

L. R. Martin

R. J. McNeal

R. X. Meyer

C. M: Randall

S. Siegel

E. T. Welmers

J. E. Wessel

M. E. Whitson

P. F. Zitte1

External

University of California, Berkeley

Department of Chemistry

Berkeley, CA 94720

Attn: C. B. Moore

University of California, Los Angeles

Department of Chemistry.

Los Angeles, CA 90024

Attn: J. V. V. Kasper

University of California

Los Alamos Scientific Laboratory

Los Alamos, NM 87544

Attn: J. H. Birely

Scientific and Tech. Info. Facility

P. O. Box 33

College Park, Md 20740

Attn: NASA Rep.
Science and Technology Division

Director of Development

DCS/R\&D

Washington; D. C. 20330

ESD (TRI)

Hanscom AF B, Mass. 01731

AFSC (DLF)

Andrews AFB, D. C. 20331

AFML (NA)

Wright-Patterson AFB, Ohio 45433

AFFDL (SU)

Wright-Patterson AFB, Ohio 45433 :

AFRPL (XP)

Edwards AFB, Calif. 93523: 


\section{External (Continued)}

AFAL (CA)

Wright-Patterson AFB, Ohio 45433

SEG (SEPI)

Wright-Patterson AFB, Ohio 45433

AF APL (NA)

Wright-Patterson AFB,

Ohio 45433

AFWL (Sul)

Kirtland AFB,

New Mex. 87117

RADC (XP)

Griffiss AFB,

N. Y. 13442

AFGL (XOP)

Hanscom AFB,

Mass. 01731

AEDC (ER)

(Library)

Arnold AFB, Tenn. 37389

National Bureau of Standards

(Library)

Washington 25, D. C. 20234 (UNC)

Naval Ordinance Lab (Tech Library)

White Oaks

Silver Springs, Md. 20919.

U.S. Army Signal Res. \& Dev't. Lab.

Data Equipment Branch

Technical Information Officer

Fort Monmouth, N. J. 07703
ONR Branch

Commanding Officer

1030 Green Street East

Pasadena, Calif. 91100

NASA (Library)

Ames Research Center

Moffett Field, Calif. 94035

NASA (Library)

Langley Research Center

Langley Field, Va. 23365

NASA (Library)

Johns on Space Center

Houston, Texas 77058

Jet Propulsion Laboratory

4800 Oak Grove Drive

Pasadena, Calif. 91103

U. S. Atomic Energy Commission

Director of Research

Washington, D. C. 20025

U.S. Atomic Energy Commission

Tech. Info. Service Extension

P. O. Box 62

Oak Ridge, Tenn. 37830

Naval Research Lab (Library)

Washington, D. C. 20025

Commanding Officer

Harry Diamond Laboratories

U. S. Army Materiel Command

Washington, D. C. 20438

Attn: Library 
External (Continued)

ERDA

Division of Physical Research

Washington, D. C. 20545

Attn: Dr. W. Haubach

\title{
Foreign
}

\author{
University of Toronto \\ Department of Chemistry \\ Toronto, M551 A1, Canada \\ Attn: J. C. Polani
}

